\title{
ANL/CHMIPP...77676
}

\section{LIQUEFACTION BEHAVIOR OF SEPARATED COAL MACERALS}

\author{
J. T. Joseph, R. B. Fisher, and C. A. Masin \\ Amoco Oil Research and Development Department, Amoco Research Center, Naperville, IL 60566
}

R. E. Winans, G. R. Dyrkacz, J. E. Hunt, and C. A. A. Bloomquist

Chemistry Division, Argonne National Laboratory, Argonne, IL 60439

In a joint program, groups at Amoco Oil and Argonne National Laboratory have elucidated the behavior of very pure coal macerals under liquefaction conditions. Macerals are microscopic distinct components of the organic matter in coals that differ in their chemical and physical properties. A new method, continuous flow density gradient centrifugation, was used to separate an Argonne Premium Coal Sample into its three main maceral groups, vitrinite, which is derived from wood, liptinites, which are derived from a number of plant sources rich in hydrogen and, finally, inertinites, which are in part fossil charcoal. In the liquefaction studies, each pure maceral was heated with a hydrogen-rich solvent and the products were analyzed.

The liquefaction yields decreased in the order: liptinite $>$ vitrinite $>$ inertinite. The liptinite provided the most oil, a material that is similar to crude oil, but also contains higher molecular weight products with large amounts of oxygen, sulfur, and nitrogen. The work showed that the macerals do not react synergistically during liquefaction. Further, the least reactive inertinites, which constitute $15 \%$ of this coal, are not converted into desirable products. Therefore, inertinite removal prior to liquefaction can potentially improve process efficiency.

This study furthered our understanding of liquefaction behavior of individual macerals, determined differences in product characteristics, and determined that interactions among the different maceral groups during liquefaction do not occur.

\section{MASTER}

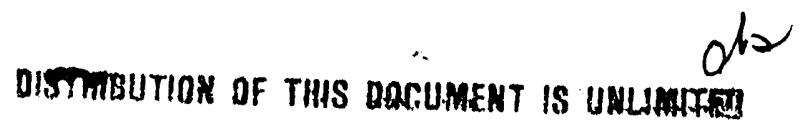




\title{
LIQUEFACTION BEHA VIOR OF SEPARATED COAL MACERALS
}

\author{
J. T. Joseph, R. B. Fisher, and C. A. Masin \\ Amoco Oil Research and Development Department, Amoco ìesearch Center, Naperville, IL 60566
}

R. E. Winans, G. R. Dyrkacz, J. E. Hunt, and C. A. A. Bloomquist
Chemistry Division, Argonne National Laboratory, Argonne. IL 60439

In a joint program, groups at Amoco Oil and Argonne National Laboratory have elucidated the behavior of very pure coal macerals under liquefaction conditions. Macerals are microscopic distinct components of the organic matter in coals which differ in their chemical and physical properties. A new method, continuous flow density gradient centrifugation, was used to separate an Argonne Premium Coal sample into its three main maceral groups, vitrinite, which is derived from wood, liptinites which are derived from a number of plant sources rich in hydrogen and, finally, inertinites which are in part fossil charcoal. In the liquefaction studies, the macerals were heated with a hydrogen rich solvent and the products separated by solubility. This study had three main objectives: (1) understand the liquefaction behavior of individual macerals, (2) determine differences in product characteristics, and (3) determine if there are interactions among the different maceral groups during liquefaction.

Macerals are microscopically distinct components of the organic matter of coal. They differ in their chemical and physical properties such as hydrogen content, aromaticity, heteroatom content, reflectance, and density. Reactivities of the macerals during liquefaction or pyrolysis are also different.

In order to better understand coal structure and its true reaction mechanisms, each maceral has to be studied independently under conditions mild enough to distinguish their reactivities. This requires separation and characterization of macerals in relatively large quantities. One approach to maceral separation is based on the differences in their densities. Density-based separation of all of the several individual macerals is difficult because of the small differences in their densities and the overlap of their density distributions. Therefore, for practical purposes, macerals of similar properties are often grouped in order of increasing density into three types: liptinites, vitrinites, and inertinites. These maceral groups can be separated in very high purity by density gradient centrifugation techniques. However, density gradient methods are not conducive to providing large amounts of low abundance macerals within a reasonable time. In these cases, either sink-float centrifugation or continuous flow centrifugation techniques are more appropriate.

One of the major objectives of this study is to better understand the liquefaction behavior of the macerals. Product yield and characteristics from each maceral type are compared with those from the whole coal. Such a comparison would help to better understand coal reaction mechanisms and to ascertain if selective removal of the less reactive maceral(s) prior to liquefaction would be beneficial. The liquefaction conditions were selected for moderate coal conversion. The intent was not to achieve maximum conversion, but to determine the reactivity differences among the macerals. It is likely that, at very high conversions, the reactivity differences between macerals will be reduced to the extent comparisons would be less meaningful.

The conversion and product distribution data from the raw and demineralized whole coal and the three maceral groups are summarized in Table 1.

\section{DISCLAIMER}

This report was prepared as an account of work sponsored by an agency of the United States Government. Neither the United States Government nor any agency thereof, nor any of their employees, makes any warranty, express or implied, or assumes any legal liability or responsibility for the accuracy, completeness, or usefulness of any information, apparatus, product, or process disclosed, or represents that its use would not infringe privately owned rights. Reference herein to any specific commercial product, process, or service by trade name, trademark, manufacturer, or otherwise does not necessarily constitute or imply its endorsement, recommendation, or favoring by the United States Government or any agency thereof. The views and opinions of authors expressed herein do not necessarily state or reflect those of the United States Government or any agency thereof. 
Table 1. Liquefaction Results from APCS 7 Coal and Macerals.

\begin{tabular}{|c|c|c|c|c|c|c|}
\hline \multirow[b]{2}{*}{ Sample } & \multirow[b]{2}{*}{ Ash, wt $\%$} & \multicolumn{5}{|c|}{ Conversion, wt\%, maf } \\
\hline & & Gas & Oil & $\mathrm{ASPH}^{\mathrm{a}}$ & $\mathrm{PA}^{\mathrm{b}}$ & Total \\
\hline whole coal, raw & 19.8 & 7 & 19 & 31 & 10 & 67 \\
\hline whole coal, demineralized & 1.0 & 5 & 9 & 36 & 20 & 70 \\
\hline liptinite & trace & 3 & 20 & 54 & 13 & 90 \\
\hline vitrinite & 0.9 & 6 & 7 & 33 & 22 & 68 \\
\hline inertinite & 2.4 & 4 & 0 & 13 & 12 & 29 \\
\hline maceral composite & 1.0 & 5 & 8 & 33 & 19 & 65 \\
\hline liptinite \& vitrinite ${ }^{\mathfrak{c}}$ & 0.8 & 6 & 9 & 36 & 21 & 72 \\
\hline
\end{tabular}

${ }^{2}$ ASPH $=$ asphaltenes.

'PA $=$ preasphaltenes.

${ }^{\mathrm{c}}$ Calculated.

Of the three maceral groups, liptinite gave the highest conversion $(90 \%)$ and the best product quality (20\% oil yield). This is not surprising because of its high hydrogen content and low carbon aromaticity. The liquefaction behavior of the vitrinite closely resembles that of the demineralized whole coal; the values for total conversion and product distribution differ only within experimental error. What is to be noted here is the large difference in oil yield between the liptinite and vitrinite. This difference is due to the difference in hydrogen contents of the two macerals. In contrast, inertinite is the least reactive of the three macerals. It gave the lowest conversion of $29 \%$ and produced no oil, which is consistent with its low hydrogen content and high aromaticity. This low yield is in spite of the fact that the inertinite contains about $0.9 \%$ iron, most likely as pyrite, which could not be removed during demineralization. It is known that pyrite can improve coal conversion. However, both liptinite and inertinite gave nearly the same amount of gases and preasphaltenes. It would be interesting to find out if preasphaltene formation from the two macerals follow similar reaction mechanisms.

The asphaltene and preasphaltene fractions were characterized by laser desorption and high resolution mass spectrometry. The laser desorption (LD) mass spectra of the toluene-soluble (asphaltenes) macerals with 308-nm irradiation are shown in Figure 1. The three different maceral groups were placed in well-defined areas on a single sample probe for the mass measurement. The laser beam was then translated to each spot to ensure identical irradiance and desorption conditions. The first striking feature is that the LD/TOF data are consistent with carbon-aromaticity and hydrogen-content data. The most significant differences among the macerals are known to be their hydrogen content and carbon aromaticity. The hydrogen content and the hydrogen/carbon ratio decrease in the order liptinite > vitrinite > inertinite, whereas the aromaticity shows the opposite trend. The inertinite, which is the least reactive maceral, is often thought to contain char-like material and large multinuclear aromatic clusters.

The LD/TOF MS of the liptinite (Figure 1a) shows a single ion series separated by 14 amu extending from $\mathrm{m} / \mathrm{z}$ 180 to 350 . This alkyl-type separation suggests a large aliphatic methylene content. This is supported by IR measurements. The number average molecular weight for the liptinite is 239 . The vitrinite (Figure $1 \mathrm{~b}$ ) and the inertinite (Figure 1c) show increasing average molecular weights of 281 and 453 . The inertinite, which is thought to contain large multinuclear aromatic clusters, shows the broadest and least well-resolved spectrum. This result implies a relatively low aliphatic content for the inertinite.

The spectra for all three preasphaltenes are very similar to those observed for the inertinite asphaltenes. However, the average molecular weight is higher, approximately 600 for all three samples. The similarity between these three samples is surprising. 
The asphaltenes were also "examined by using direct-probe, high-resolution mass spectrometry (HRMS). In the analysis, the data are sorted by heteroatom type and hydrogen deficiency (sum of rings plus double bonds). Figure 2 shows a summation of the data for the vitrinite and inertinite. Both samples contain a significant amount of oxygen containing species. However, there is more aliphatic material in the vitrinite and more polycyclic aromatic compounds in the inertinite. There are significant peaks (approximately 1\% yield) for two-, three-, four-, and five-ring compounds. In Table 2 are listed prominent species with possible structure assignments for $\mathrm{HD}=17$ (five rings). Significant amounts of heteroatom-containing species appear in these materials.

Table 2. Prominent series of peaks for $\mathrm{HD}=17$ in the inertinite asphaltenes from HRMS.

Parent Side-Chain Carbons Mole Percent Possible Structure

(12)

Three maceral groups, namely liptinite, vitrinite, and inertinite from West Virginia. Lewiston-Stockton coal, were isolated for the first time, using a continuous flow centrifuge method. These macerals undergo pyrolysis and hydroliquefaction independently of one another. The extent of weight loss in pyrolysis and conversion in 
liquefaction of the macerals parallels the hydrogen and the aliphatic carbon contents of the macerals. Thus, the reactivities of the three macerals decrease in the order liptinite $>$ vitrinite $>$ inertinite. The least reactive inertinite has been projected to have little influence on conversion and product distribution of the whole APCS 7 coal. 

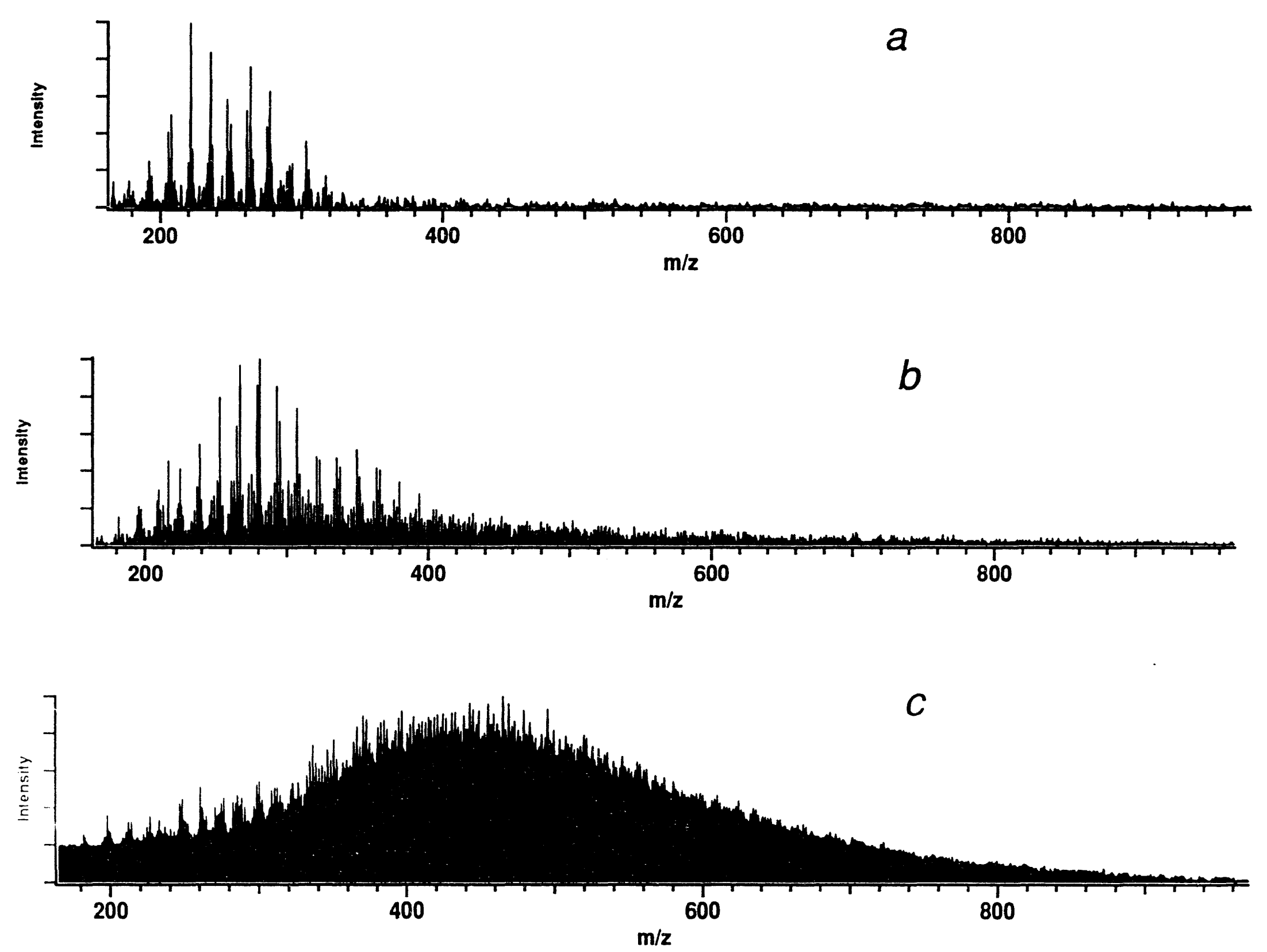

Figure 1. Laser desorption mass spectra of asphaltene fractions. (a) liptinite, (b) vitrinite, (c) inertinite 

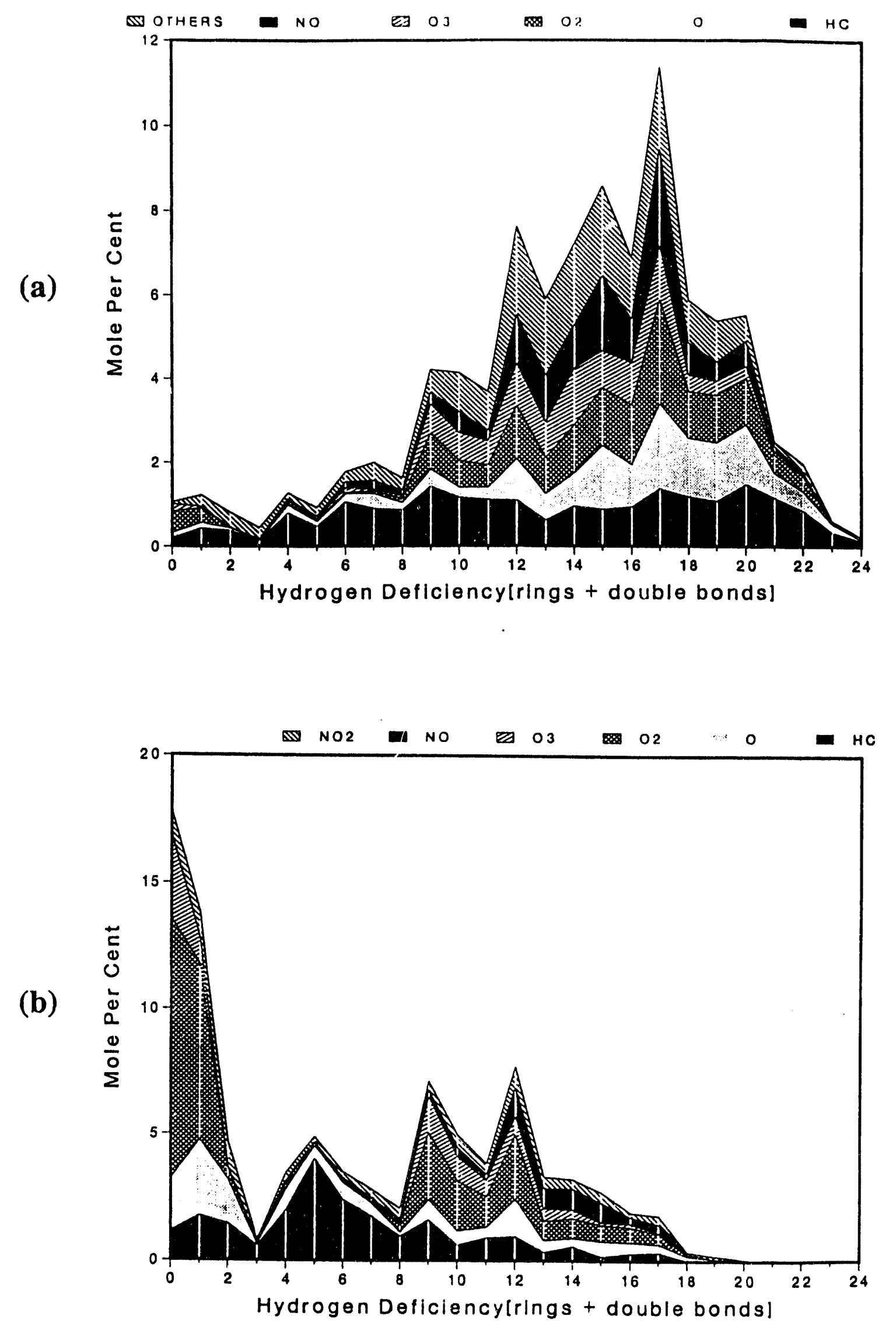
Figure 2. Distribution of volatile speries determined by HRMS from the asphaltene fractions of (a) inertinite
and (b) vitrinite. 

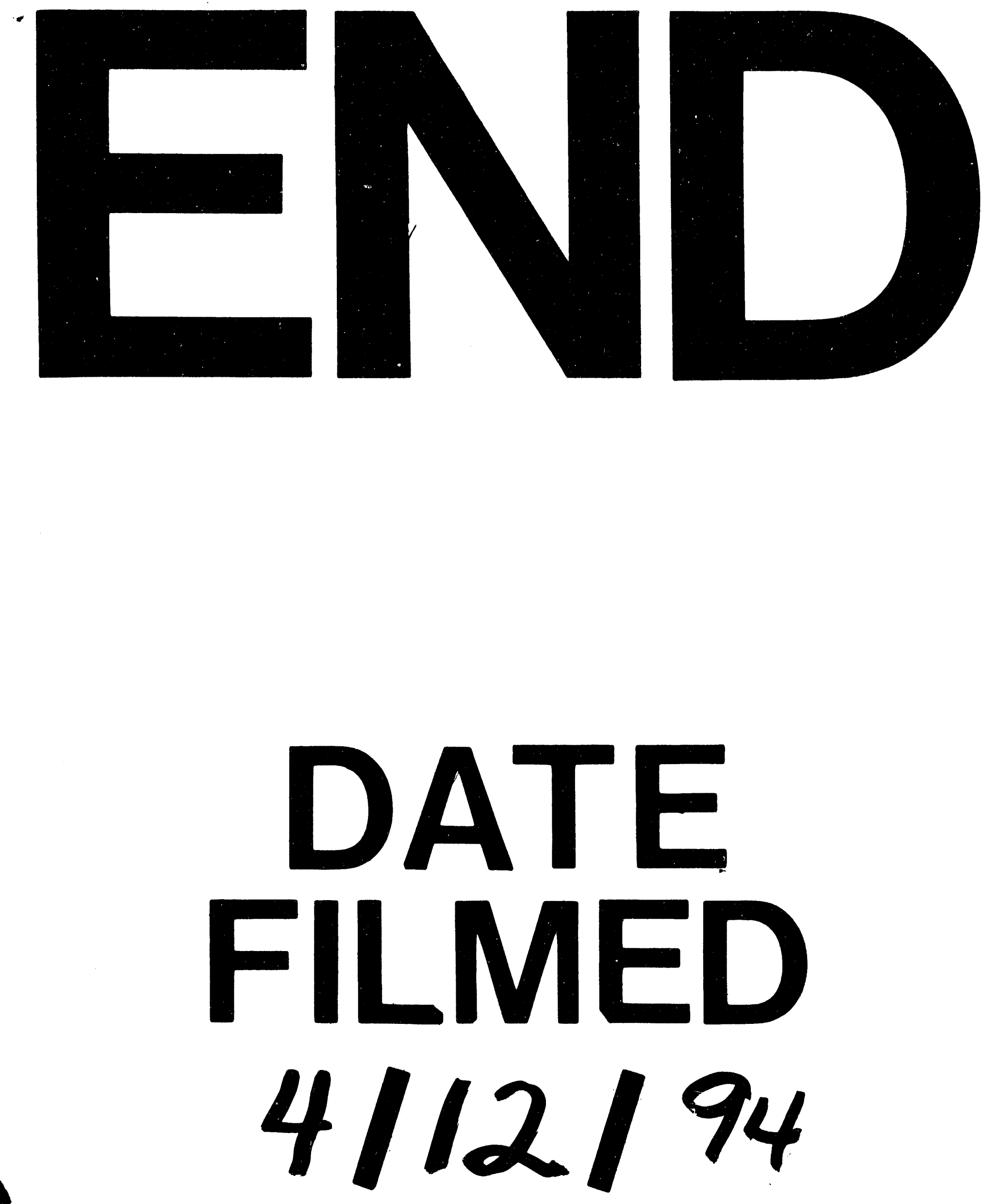

1 
